\title{
ToF-SIMS analysis of influence of alkylamine compounds in UPW on hydrogen-terminated Si surface
}

\author{
Junji Kobayashi* \\ Advanced Technology RED Center, Mitsubishi Electric Corporation, \\ Tsukaguchi-hommachi 8-1-1, Amagasaki, Hyogo 661-8661, Japan, and \\ Institute of Industrial Science, The University of Tokyo, \\ Komaba 4-6-1, Meguro-ku, Tokyo 153-8505, Japan
}

Masanori Owari

Environmental Science Center, The University of Tokyo, Hongo 7-3-1, Bunkyo-ku, Tokyo113-0033, Japan

(Received 25 October 2006; Accepted 5 December 2006; Published 12 December 2006)

\begin{abstract}
Adsorption behaviors of alkylamine compounds in UPW (ultra pure water) on hydrogen-terminated $\mathrm{Si}(100)$ were elucidated mainly by ToF-SIMS. Si wafers cleaned by heat treatment in $500^{\circ} \mathrm{C}$ were etched in $0.38 \% \mathrm{HF}$ and soaked in water solution of alkylamine after $1 \mathrm{~min}$ UPW rinse. The peak intensity of amine molecular ions and $\mathrm{SiH} / \mathrm{Si}$ ratio detected by ToF-SIMS are considered to be used as a measure of quantity of adsorbed molecules and surface oxidation, respectively. It was found that hydrophobic amine molecules with longer $\mathrm{CH}_{2}$ chain tend to be left with high concentration in a very short time of soaking and also tend to have the larger effect on the increase of surface oxidation of hydrogen-terminated surface. The latter phenomenon was explained by an I-effect of alkyl group. [DOI: $10.1380 /$ ejssnt.2006.644]
\end{abstract}

Keywords: Secondary ion mass spectrometry; Surface chemical reaction; Silicon; Si(100); Amine; ToF-SIMS

\section{INTRODUCTION}

It has been widely recognized that organic molecules adsorbed on hydrogen-terminated silicon surface form Si$\mathrm{C}$ bond after thermal desorption of surface hydrogen atom and degrade the electrical property of $\mathrm{Si}$ device $[1,2]$. In general, it has been thought that the source of organic contamination is airborne molecular organic materials, and the understanding of influence of the variety of additives in plastic materials such as carrier box and building materials of clean room has been extensively studied mainly using the combined technique of gas chromatography-mass spectrometry (GC-MS) and wafer thermal desorption (WTD) [3-5]. Another source of organic contamination is ultra pure water (UPW) widely used in wet cleaning processes. Organic impurities on wafer surface after rinsing in UPW at a final stage of wet cleaning have not been fully investigated because the surface after rinsing has been considered as a starting surface to airborne contamination and no analytical techniques have been developed for the investigation [6-10]. The maintenance of surface cleanness and defect control of hydrogen-terminated surface in wet cleaning processes are needless to say important and the understanding of the adsorption property and the influence of organic impurities in UPW have been required.

We have established a new technique of ToF-SIMS analysis of trace organic adsorbent on the native oxide surface soaking in UPW after high temperature heat cleaning and have investigated peculiar adsorption behaviors of alkylamine compounds supposed as organic impurity in UPW in the previous report [9]. It has been found

\footnotetext{
*Corresponding author:

Kobayashi. Junji@da.MitsubishiElectric.co.jp
}

that the adsorption behaviors are definitely dependent on the numbers of carbon atoms and the water rinse process could result in the wafer surface being more contaminated from the organic point of view. Takahagi, et al. indicated that surface organic contamination acted as an etching mask and led to irregular morphology on the wafer surface in the investigation of atomic-scale smooth hydrogenterminated surface using ammonium fluoride aqueous solution $[11,12]$. Sugita, et al. studied the initial oxidation on hydrogen-terminated surface using in-situ infrared attenuated total reflection spectroscopy (ATR) and found that the back bond and $\mathrm{Si}-\mathrm{H}$ bond were oxidized by the reaction of impurity as oxidant in water [13].

In this work, we adopted the ToF-SIMS method combined with wafer soaking treatment to the investigation of adsorption property of alkylamine compounds on hydrogen-terminated Si(100). ToF-SIMS has the specific features that can estimate the relative quantity of trace amine adsorbed on wafer surface and can also estimate the chemical change of the substrate surface such as oxidation of hydrogen-terminated surface at the same time, especially is considered as a very powerful tool to study influence of trace organic impurities in water to hydrogenterminated surface due to the ability of detection of $\mathrm{SiH}$ based fragment. In addition, it is inferred that the adsorption behavior of the same amine compounds is different between on hydrophilic oxidized surface and on hydrophobic hydrogen-terminated surface.

It was found that alkylamine compounds in UPW caused the increase of oxidation rate of hydrogenterminated $\mathrm{Si}(100)$ and hydrophobic alkylamine compounds may be left on the surface in high concentration in wet cleaning process in the very short time. Both results could degrade the device performance because the former result may cause the irregular oxidation thickness and the latter may cause point defect due to formation of Si-C bond. We concluded that the highly hydropho- 

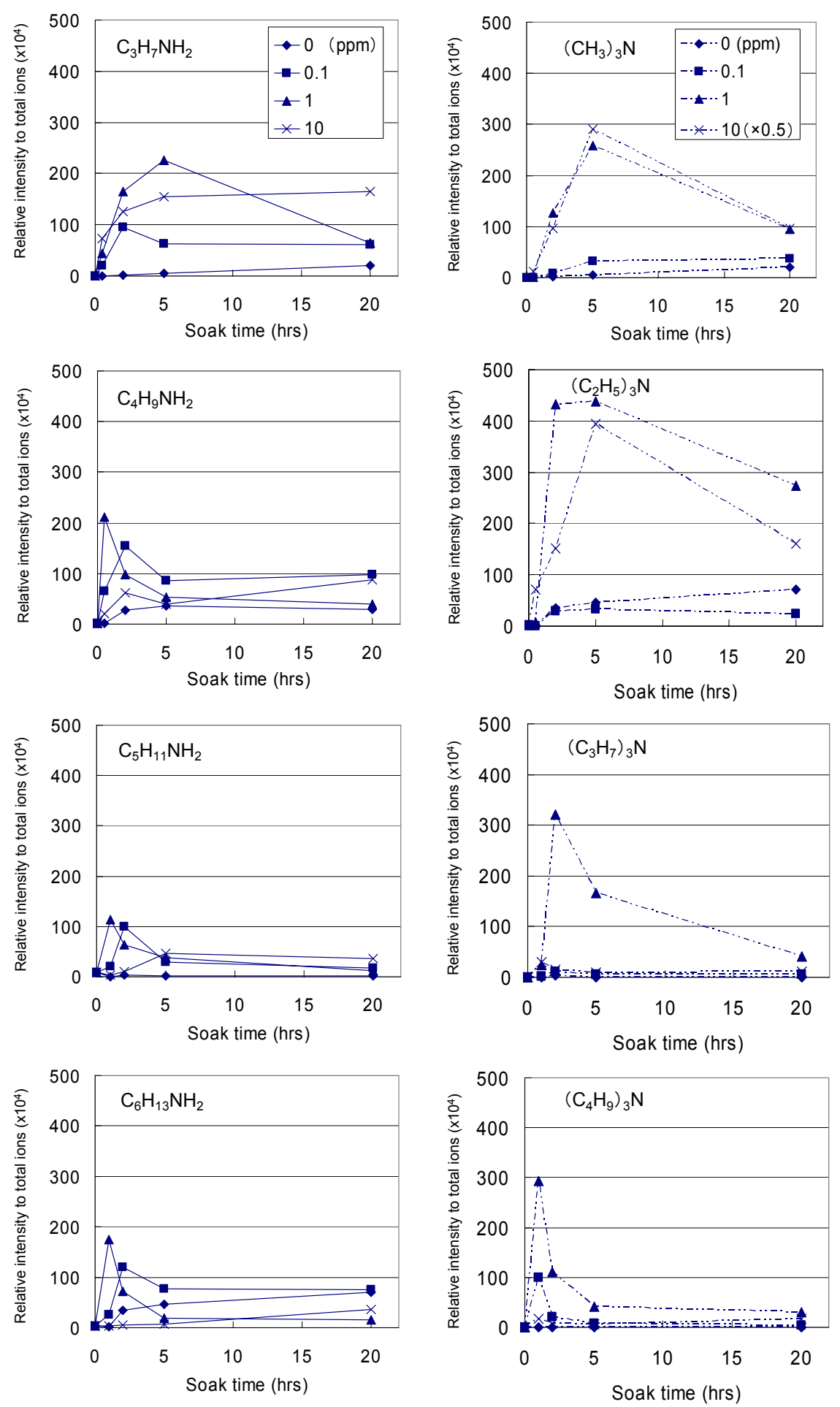

FIG. 1: The dependence of respective amine molecular peak intensity detected by ToF-SIMS on the time of wafer soaking in water solution of primary and tertiary amine compounds.

bic amine should be eliminated from water used in wet cleaning process.

\section{EXPERIMENTAL}

Two types of amine compounds were used as model compounds for water-soluble amines: the primary amines $\mathrm{C}_{n} \mathrm{H}_{2 n+1} \mathrm{NH}_{2} \quad(n: 3-7)$ and the tertiary amines
$\left(\mathrm{C}_{n} \mathrm{H}_{2 n+1}\right)_{3} \mathrm{~N}(n: 1-4)$. The solubility of these compounds in water is lower than $0.1 \mathrm{~g} / 100 \mathrm{~mL}$. The UPW solutions of the respective amines were prepared in concentration of $100 \mathrm{ppb}, 1 \mathrm{ppm}$ and $10 \mathrm{ppm}$.

Silicon wafers $(\mathrm{Si}(100), 50 \mu \mathrm{m}$ thick) kept in the plastic cassette were used as the adsorption surface and the wafer was heated at high temperature of $500^{\circ} \mathrm{C}$ in the $\mathrm{He}$ atmosphere in order to remove organic contamination [9]. Immediately after cooling to approximately $150^{\circ} \mathrm{C}$ in 

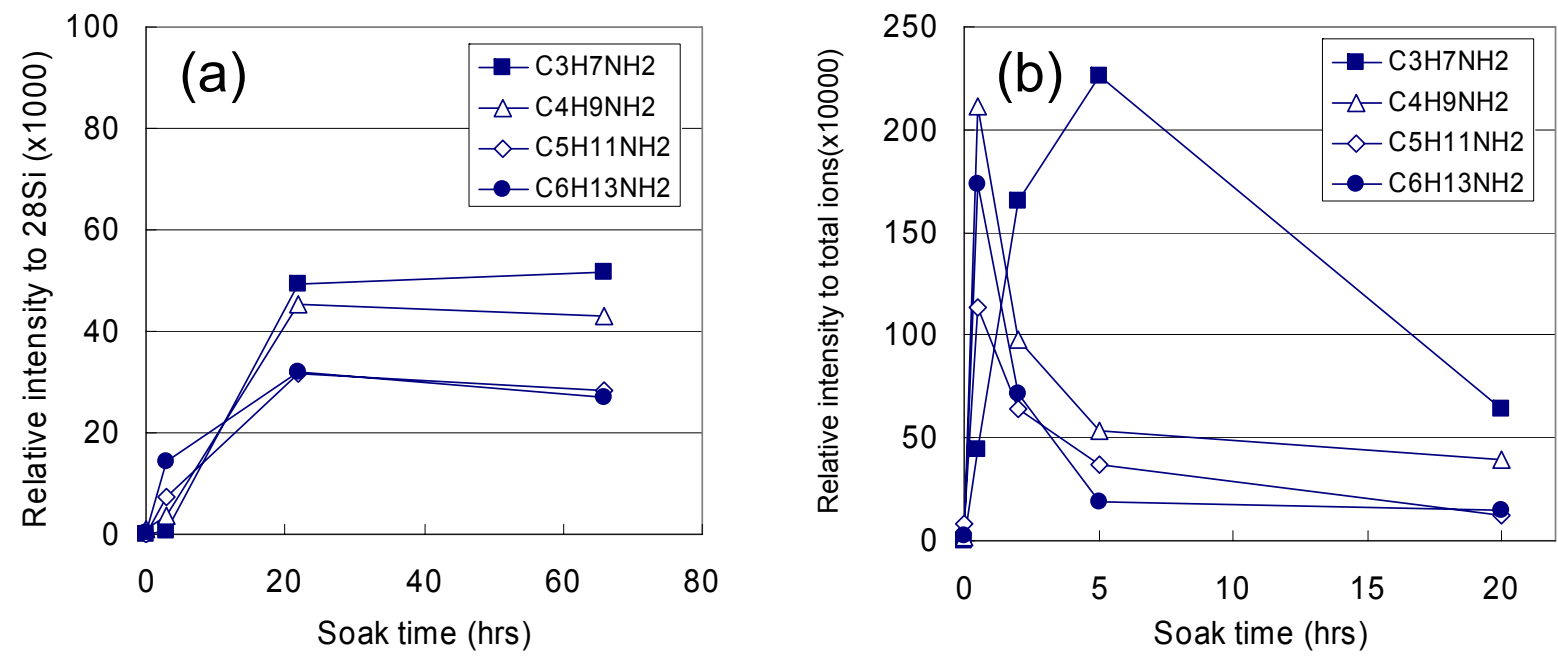

FIG. 2: The dependence of molecular peak intensity on (a) the native oxide (hydrophilic) and (b) HF etched (hydrophobic) surface on the time of wafer soaking in water solution of amine concentration of $1 \mathrm{ppm}$.

the same atmosphere, the wafer was cut into $10 \mathrm{~mm} \times 10$ mm small pieces in the clean bench. After 5 min soak in dilute $\mathrm{HF}$ solution $\left(\mathrm{HF}(38 \%): \mathrm{H}_{2} 0=1: 100\right)$ and 1 min rinse by UPW, respective wafer pieces were put into $30 \mathrm{cc}$ glass vials, and capped with plastic cap sealed with aluminum foil.

The prepared UPW (resistivity> $18 \mathrm{M} \Omega \mathrm{cm}$ ) solution of each amine compounds was poured into the vial with a wafer piece. After pouring, the wafer piece was carefully placed with mirror surface up. After the fixed soak time, the wafer piece was put out of vial and water solution on the wafer piece was removed using $\mathrm{N}_{2}$ gas, and the wafer piece was mounted in the sample case for ToFSIMS measurements. These procedures were carried out in clean room of class 1000 . ToF-SIMS measurements were performed using PHI TRIFT II apparatus. Primary beam of $\mathrm{Ga}^{+}$ions with $15 \mathrm{keV}$ acceleration was used. The square area with the side of $50 \mu \mathrm{m}$ was irradiated by pulses of $\mathrm{Ga}^{+}$ions. The secondary ions from the same $50 \mu \mathrm{m}$ square region were detected during the first $5 \mathrm{~min}$. At least two measurements were made in the same sample and measurement errors were less than 5\% among these measurements. We performed x-ray photoelectron spectroscopy (XPS) measurement of $\mathrm{Si} 2 p$ region for the parts of samples above-mentioned in the area of $200 \mu \mathrm{m}$ square by monochromatized Al-K $\alpha$ source $(1486.6 \mathrm{eV})$ using PHI QUANTUM 2000 apparatus.

\section{RESULTS AND DISCUSSION}

\section{A. Adsorption property of amine compounds on hydrogen-terminated $\mathrm{Si}(100)$ in water}

Figure 1 shows the dependence of respective molecular peak intensities on the time of wafer soaking in water solution of respective primary and tertiary amine compounds. Mass numbers derived from measured molecular peaks are $60.12\left(\mathrm{C}_{3} \mathrm{H}_{7}-\mathrm{NH}_{3}^{+}\right), 74.14\left(\mathrm{C}_{4} \mathrm{H}_{9}-\mathrm{NH}_{3}^{+}\right)$, $88.17\left(\mathrm{C}_{5} \mathrm{H}_{11}-\mathrm{NH}_{3}^{+}\right)$and $101.20\left(\mathrm{C}_{6} \mathrm{H}_{13}-\mathrm{NH}_{3}^{+}\right)$for the pri-

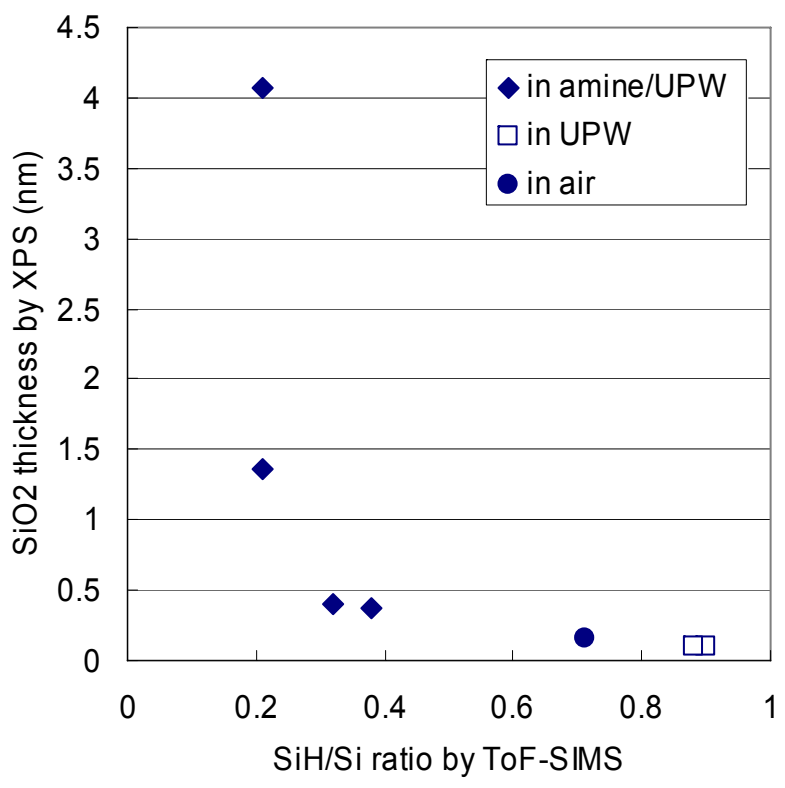

FIG. 3: Oxide film thickness induced from Si2 $p$ XPS peak intensity as a function of ${ }^{29} \mathrm{SiH} /{ }^{28} \mathrm{Si}$ peak intensity ratios detected by ToF-SIMS. The samples used were oxidized under different environment.

mary amines, and $60.12\left(\left(\mathrm{CH}_{3}\right)_{3}-\mathrm{NH}^{+}\right), 102.20\left(\left(\mathrm{C}_{2} \mathrm{H}_{5}\right)_{3^{-}}\right.$ $\left.\mathrm{NH}^{+}\right), 144.28\left(\left(\mathrm{C}_{3} \mathrm{H}_{7}\right)_{3}-\mathrm{NH}^{+}\right)$and $186.36\left(\left(\mathrm{C}_{4} \mathrm{H}_{9}\right)_{3}-\mathrm{NH}^{+}\right)$ for the tertiary amines. Peak intensity is represented as relative intensity to total ions.

In the cases of propylamine $\left(\mathrm{C}_{3} \mathrm{H}_{7} \mathrm{NH}_{2}\right)$, trimethylamine $\left(\left(\mathrm{CH}_{3}\right)_{3} \mathrm{~N}\right)$ and triethylamine $\left(\left(\mathrm{C}_{2} \mathrm{H}_{5}\right)_{3} \mathrm{~N}\right)$, the increase of peak intensity at the initial 5 hours are observed and may be approximated as Langmuir adsorption. However, including relatively long soaking time of these three compounds, the peak intensity of the other amine compounds decrease even after the very beginning soaking time, especially, in the cases of amines with the large numbers of carbon atoms such as penthylamine $\left(\mathrm{C}_{5} \mathrm{H}_{11} \mathrm{NH}_{2}\right)$, hexylamine $\left(\mathrm{C}_{6} \mathrm{H}_{13} \mathrm{NH}_{2}\right)$ tripropylamine $\left(\left(\mathrm{C}_{3} \mathrm{H}_{7}\right)_{3} \mathrm{~N}\right)$ and 

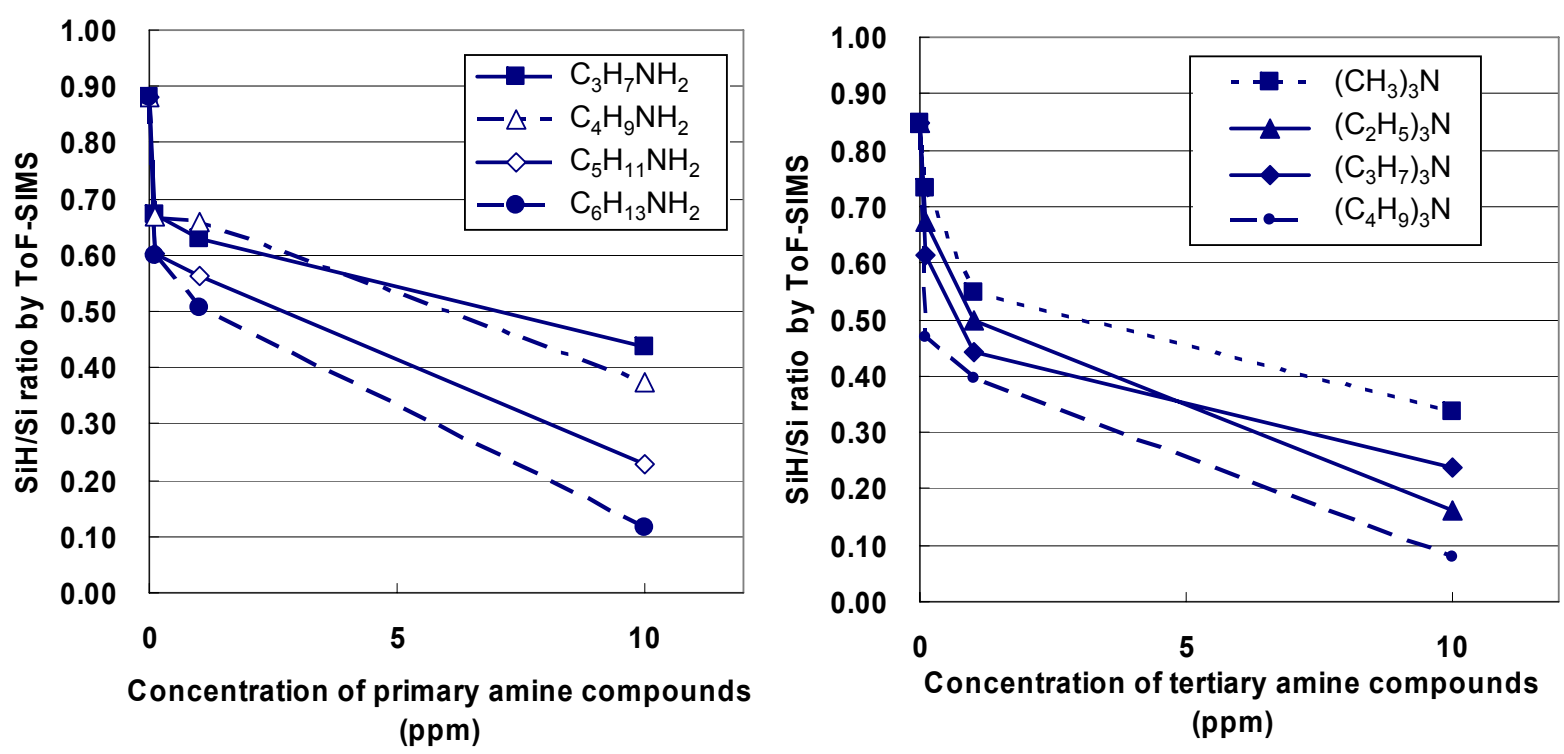

FIG. 4: The ${ }^{29} \mathrm{SiH} /{ }^{28} \mathrm{Si}$ ratio detected by ToF-SIMS on hydrogen-terminated silicon surface after 0.5 hrs soaking in water solution of primary (left) and tertiary (right) amines as a function of amine concentration.

tributylamine $\left(\left(\mathrm{C}_{4} \mathrm{H}_{9}\right)_{3} \mathrm{~N}\right)$. It can be also seen that there are no clear dependence between amine concentration and peak intensity within the respective compounds, and we can notice that there are the cases that the peak intensity of the alkylamine with lower concentration is rather higher than with higher concentration, for example for hexylamine and tributylamine. These complicated adsorption behaviors are thought to be mainly due to the change that the hydrogen-terminated surface is oxidized in water and become hydrophilic.

In order to compare these adsorption behaviors with the ones of the same compounds on native oxide surface that is hydrophilic, we show the dependence of molecular peak intensity on the time of wafer soaking on both the hydrophilic (a) and hydrophobic (b) surfaces in the same concentration of 1 ppm in Fig. 2.

It should be noticed that initial changes of molecular peak intensities on the time of wafer soaking are very different between hydrophilic and hydrophobic surface. While adsorbed quantities on hydrophobic surface decreased except for tripropylamine, those on hydrophilic surface increased as the increase of the soaking time. The adsorption behaviors on the hydrophilic surface have been investigated in the previous paper [9] and we indicated that there seems to be a good relationship between the octanol-water partition coefficients and peak intensity ratios of $24 \mathrm{~h}$ soaked to $2 \mathrm{~h}$ soaked. It was considered that the amines with large octanol-water partition coefficient are likely to be adsorbed physically on wafer surface at short soaking time because being not stable in water and replaced with the amines which have small octanol-water partition coefficients and high adsorption energy on hydrophilic wafer surface in long soaking time.

We considered that in the case of hydrophobic surface, amine compounds with a long $\mathrm{CH}_{2}$ chain also tend to be adsorbed initially because they are more stable than in water and when wafer surface becomes hydrophilic, they tend to desorb from the surface. Also in the tertiary amines, we have observed the same trend as in the primary amines, though the decrease of peak intensity has been seen at relatively large molecules such as tripropylamine and tributylamine in the long soaking time.

The above result that large molecular amines with more hydrophobic nature tends to be adsorbed with high concentration (even though we cannot define absolute value at present) on the hydrophobic surface in the short time suggests that it is important to eliminate these hydrophobic amines from UPW used in actual wet cleaning process for Si device manufacturing.

\section{B. Oxidation rate of hydrogen-terminated $\mathrm{Si}(100)$ in water solution of alkylamines}

It was found that hydrophobic amines once adsorbed on hydrogen-terminated surface desorb as the surface becomes hydrophilic in other words, oxidized. We may infer that the oxidation process of hydrogen-terminated surface may be represented as the change of $\mathrm{SiH}$-based peak intensity due to ToF-SIMS. Figure 3 shows the relationship of $\mathrm{SiH} / \mathrm{Si}$ peak intensity ratios detected by ToF-SIMS with oxide film thickness induced from $\mathrm{Si} 2 p$ XPS peak intensity. The samples used were oxidized under different environment as shown in Fig. 3. It is found that $\mathrm{SiH} / \mathrm{Si}$ ratio due to ToF-SIMS has a good correlation with oxide thickness above approximately 0.2 as the value of $\mathrm{SiH} / \mathrm{Si}$ ratio. We suppose that the depth investigated by ToFSIMS is about $1 \mathrm{~nm}$ and $\mathrm{SiH} / \mathrm{Si}$ ratio can be used as an indication of oxidation below $1 \mathrm{~nm}$ of oxide thickness. In other words, $\mathrm{SiH} / \mathrm{Si}$ ratio saturates and cannot be used as an indication at an oxide deeper than so-called native oxide (about $1 \mathrm{~nm}$ depth). SiH fragment is not only due to $\mathrm{SiH}$ at the hydrogen-terminated surface bonding. Siloxane molecules adsorbed on silicon surface, for example, give the same fragment. We need to eliminate the other surface contamination as possible as we can, in order to 

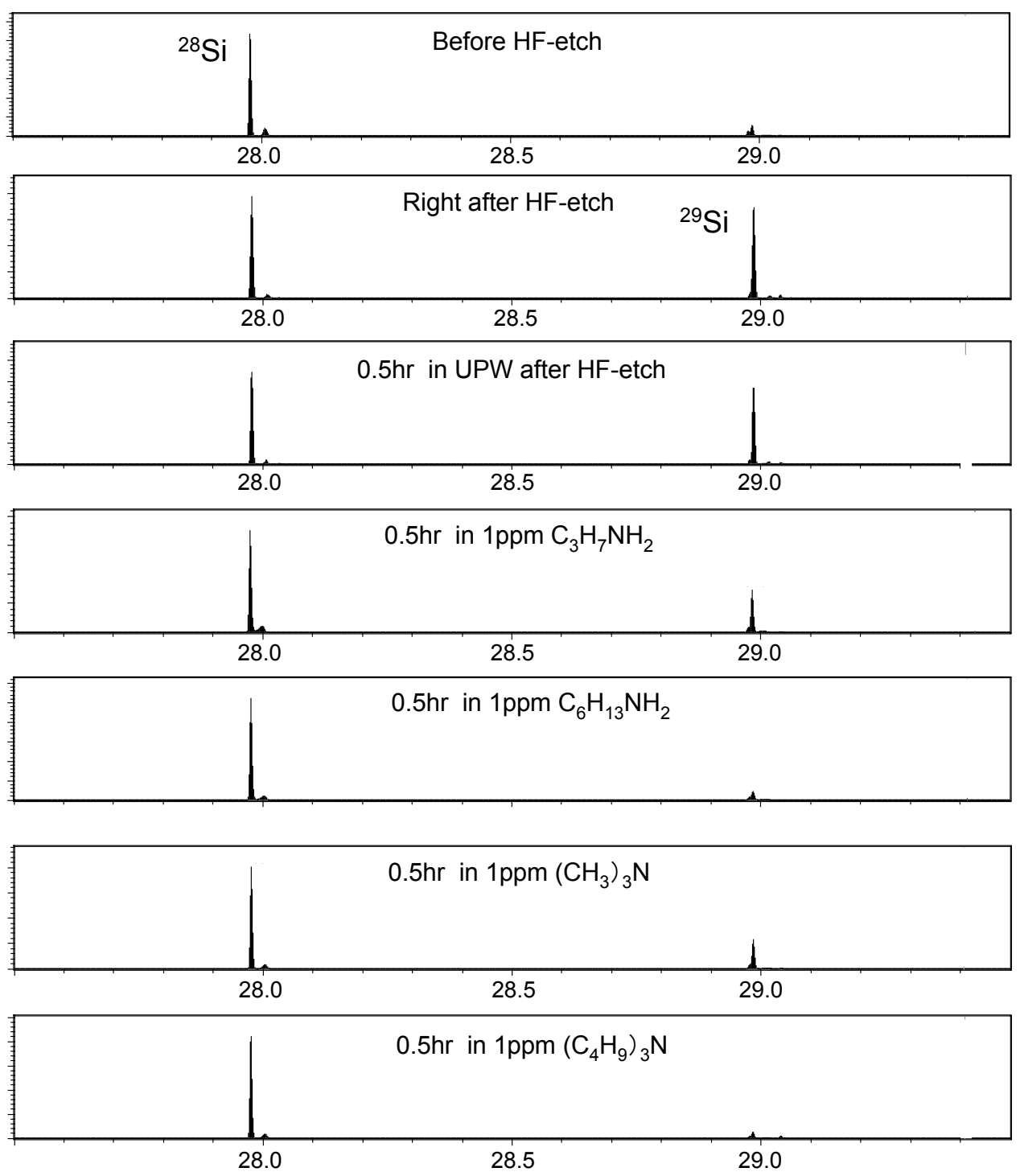

FIG. 5: ToF-SIMS spectra including the region of the ${ }^{28} \mathrm{Si}$ and ${ }^{29} \mathrm{SiH}$ peaks for the same sample used in Fig. 4.

realize detailed investigation of surface oxidation by ToFSIMS. At least two times of experiments were performed under the conditions with this requirement satisfied.

Figure 4 shows amine concentration dependence of the ${ }^{29} \mathrm{SiH} /{ }^{28} \mathrm{Si}$ ratio on hydrogen-terminated silicon surface after $0.5 \mathrm{hrs}$ soaking in water solution of primary (left) and tertiary (right) amine by ToF-SIMS. Figure 5 shows the actual ToF-SIMS spectra including the region of the $\mathrm{Si}$ and $\mathrm{SiH}$ peaks for the same sample used in Fig. 4.

Right after $\mathrm{HF}$ etching, the $\mathrm{SiH} / \mathrm{Si}$ ratio is approximately 0.90 (data not shown), and after 0.5 hrs soaking in UPW (which corresponds to $0 \mathrm{ppm}$ in $x$-axis both in Fig. 4 ), only a slight decrease of this ratio is observed. When amine of $100 \mathrm{ppb}$ concentration was added to UPW, the ratio decreased dramatically to about between 0.6 and 0.7 for primary amines and to about between 0.5-0.7 for tertiary amines. As the concentration of amine compounds increase, $\mathrm{SiH} / \mathrm{Si}$ ratio decreases to less value. We can infer that oxidation rate of hydrogen-terminated $\mathrm{Si}(100)$ surface increases due to addition of amine compounds in UPW. In addition, it is clearly observable from Fig. 4 that the degree of the increase of oxidation rate is dependent on species of amine compounds, i.e., amine molecules with more numbers of alkyl groups and longer alkyl chain have the larger effect to the increase of oxidation rate, even though not perfectly said, for example as the case in between trimethylamine and tripropylamine at $10 \mathrm{ppm}$ addition.

As mentioned at the previous section, this type of amine compounds (which is thought to be more hydrophobic from a simple assumption that the non-polar group such as alkyl group brings about hydrophobic nature for a molecule) tends to be adsorbed in high concentration initially, and desorb from surface as the oxidation of the surface proceeds. Therefore, we can suppose that initial adsorption of these amines causes high speed oxidation of hydrogen-terminated surface and as a result of that, hydrophobic amine desorb dramatically from hydrophilic surface which was hydrophobic before the amine molecules were adsorbed. It is suggested from these results that alkylamine molecules behave like catalyst for oxidation reaction of hydrogen-terminated silicon surface 
and cause the inhomogeneous oxide thickness and imperfect passivation to water and oxygen.

There may be two possible assumptions explaining how alkylamine compounds increase the rate of oxidation of hydrogen-terminated surface [14-25]. The first one is that the concentration of $\mathrm{OH}^{-}$ion increases near silicon surface by the effect of basic alkylamine and $\mathrm{Si}-\mathrm{H}$ groups are replaced by $\mathrm{Si}-\mathrm{OH}$ groups due to nucleophilic attack of $\mathrm{OH}^{-}$ions on Si-H bond [17]. The second is that lone pair of nitrogen atom of alkylamine compounds works as acceptor of hydrogen in Si-H due to nucleophilic effect (what we call, I-effect), the dangling bond of Si is formed at one bond among two Si-H bonds of surface dihydride, and these unstable states of surface silicon hydride cause additional reaction between surface sites $\left(\mathrm{Si}^{-}\right.$, and $\mathrm{Si}-\mathrm{Si}$ backbonds) and attacker molecules $\left(\mathrm{H}_{2} \mathrm{O}, \mathrm{OH}^{-}\right.$, or dissolved oxygen) due to the polarization of surface sites [22].

A basicity constant $\left(\mathrm{p} K_{b}\right)$ as a measure of basicity is known for some alkylamine compounds used in this work: 0.6 for trimethylamine, 4.1 for propylamine, 4.5 for tripropylamine, 4.8 for butylaminen, and 5.6 for triethylamine, in the order from small $\mathrm{p} K_{b}$. When it was supposed that the strong base cause large effect on the increase of oxidation rate of the passivated surface, we cannot explain that trimethylamine which is the particularly weakest base among amines above, has the larger effect than propylamine and butylamine have. It is wellknown that small $\mathrm{p} K_{b}$ of tertiary amines is due that these molecules need more water molecules than primary amines does in solvation by water molecules in the proton dissociation [26]. The $\mathrm{p} K_{b}$ is of course deeply related to I-effect of alkyl group in amine molecules. Therefore, we can explain the increase of oxidation rate by both two assumptions above. In any case, hydrophobic alkylamine could approach to the hydrogen-terminated surface, and cause the promotive effect on the oxidation of the surface mainly due to I-effect.

\section{CONCLUSIONS}

We investigated the adsorption behavior of alkylamine compounds in UPW on hydrogen-terminated $\mathrm{Si}(100)$ by ToF-SIMS. It was found that alkylamine compounds in UPW caused the increase of oxidation rate of hydrogenterminated $\mathrm{Si}(100)$ and hydrophobic alkylamine compounds may be left on the surface in high concentration in wet cleaning process in the very short time. The former phenomenon can be explained mainly by the I-effect of alkylamine. Both results could degrade the device performance because the former result may cause the irregular oxidation thickness and the latter may cause point defect due to formation of Si-C bond. It is concluded that it is important to eliminate these hydrophobic amines from UPW used in the wet cleaning process for Si device manufacturing.
[1] S. R. Kasi, M. Liehe, P. A. Thiry, H. Dallaporta and M. Offenberg, Appl. Phys. Lett. 59, 1991 (1991).

[2] N. B. Rana, and F. Shadman, IEEE. Trans. Semicon. Manufacturing 16, 76 (2003).

[3] H. Miya, R. Sasajima, E. Tkakami, N. Nakamura and T. Takahagi, Jpn. J. Apple. Phys. 44, 3864 (2005).

[4] T. Takahagi, S. Shingubara, H. Sakaue, K. Hoshino and H. Yashima, Jpn. J. Appl. Phys. 35, L818 (1996).

[5] T. Ogata, C. Ban, A. Ueyama, S. Muranaka, T. Hayashi, K. Koabayashi, J. Koabayashi, H. Kurokawa, Y. Ohno and M. Hirayama, Jpn. J. Appl. Phys. 37, 2468 (1998).

[6] A. Karen, K. Ozawa and A. Ishitani, SIMS XI., (Wiley, New York, 1998) p. 229.

[7] A. Karen, N.Man, T. Shibamori and K. Takahashi, Appl. Surf. Sci. 203-204, 541 (2003).

[8] T. Shibamori, Y. Muraji, N. Man and A. Karen, Appl. Surf. Sci. 203-204, 449 (2003).

[9] J. Kobayashi and M. Owari, Surf. Interf. Anal. 38, 305 (2006).

[10] T. Imaoka, A. Umeka and T. Futasaki, Semiconductor Pure Water and Chemicals Conference, Water Session 1993 CONF12//WAT, 1993; pp.93-116.

[11] H. Sakaue, S. Fujiwara, S. Shingubara and T. Takahagi, Appl. Phys. Lett. 78, 309(2001)

[12] T. Takahagi, I. Nagai, A. Ishitani, H. Kuroda and Y. Nagasawa, J. Appl. Phys. 64, 3516 (1988).

[13] Y. Sugita and S. Watanabe, Jpn. J. Appl. Phys. 37, 3272 (1998).
[14] K. Endo, K. Arima, K. Hirose, T. Kataoka and Y. Mori, J. Appl. Phys. 91, 4065 (2002).

[15] T. Konishi, T. Yao, M. Tajima, H. Ohsima, H. Ito and T. Hattori, Jpn. J. Appl. Phys. 31, L1216 (1992).

[16] V. A. Burrows, Y. J. Chabal, G. S. Higashi, K. Raghavachari and S. B. Christman, Appl. Phsy. Lett. 53, 998 (1988).

[17] D. Graf, M. Grundner and R. Shluz, J. Vac. Sci. Technol. A 7, 808 (1989).

[18] T. Miura, M. Niwano, D. Shoji and N. Miyamoto, J. Appl. Phys. 79, 4373 (1996).

[19] Y. Sugita and S. Watanabe, Jpn. J. Appl. Phys. 38, 2427 (1999).

[20] Y. Sugita and S. Watanabe, Jpn. J. Appl. Phys. 37, 1193 (1998).

[21] M. Morita, T. Ohmi, E. Hasegawa, M. Kawakami and M. Ohwada, J. Appl. Phys. 68, 1272 (1990).

[22] M. Morita, T. Ohmi, E. Hasegawa, M. Kawakami and K. Suma, J. Appl. Phys. 55, 562 (1989).

[23] T. Takahagi, H. Sakaue and S. Shingubara, Jpn. J. Appl. Phys. 40, 6198 (2001).

[24] A. Yoshigoe and Y. Teraoka, Jpn. J. Appl. Phys. 42, 5749 (2003).

[25] H. Jungblut, D. Wille and H. J. Lewerenz, Appl. Phys. Lett. 78, 168(2001).

[26] F. E. Condon, J. Amer. Chem. Soc. 87, 4481 (1965). 